\title{
PANDANGAN ULAMA TENTANG IQTIBAS DENGAN AYAT AL QUR'AN DAN HADITS NABI SAW
}

\author{
ERWIN SURYANINGRAT
}

\begin{abstract}
A few centuries after the demise of the Qur'an, the scholars formulated language, usub and literature in order to study and deepen the content of the Qur'an, which gave rise to many scientific disciplines, among others in the field of language studies, nahwu and sorof, related to the style of language and literature was born balaghoh discipline with branches of study, ma'ani, bayan and badi '. In Badi Science, iqtibas is defined as follows "The speaker saves his prose or poem with something from the Qur'an or Hadith in a way that does not signal that something comes from both." Qaidah The science of Badi allows mutakallim (speaker) to change a little on the word taken from the Qur'an or Hadith, that is due to the adjustment of wazan or other causes. Iqtibas with the text of the Qur'an and sunna is not prohibited and forbidden in absolute terms, it is permissible but must be with caution.
\end{abstract}

Kata Kunci: hukum, Iqtibas, al-Qur'an hadits

\section{A. PENDAHULUAN}

Sejak zaman dahulu, sejak al-Qur'an diturunkan banyak orang yang terkagum-kagum dengan susunan bahasa al-Qur'an dan keindahan uslubnya, bahkan banyak diantara mereka mencoba untuk menandingi ketinggian bahasa Al- Qur'an seperti nabi-nabi palsu yang mencoba untuk membuat ayat-ayat yang semisal dengan al-Qur'an, namun semua yang mereka lakukan menemui kegagalan dan tidak mungkin dapat menandingi al-Qur'an.

Sekian abad setelah diturunkannya Al-Qur'an, para ulama bahasa merumuskan kaedah-kaedah bahasa, uslub dan sastra dalam rangka mengkaji dan mendalami isi kandungan al-Qur'an, sehingga memunculkan banyak disiplin keilmuan, diantaranya dalam bidang kajian 
kebahasaan ada nahwu dan sorof, terkait dengan gaya bahasa dan sastranya lahirlah disiplin ilmu balaghoh dengan cabang kajianya, ma'ani, bayan dan badi'.

Terutama pada kajian ilmu badi', dijelaskan bahwa;

“ilmu badi' adalah suatu ilmu yang dengannya diketahui segi-segi (beberapa metode dan cara-cara yang ditetapkan untuk menghiasi kalimat dan memperindahnya) dan keistimewaan-keistimewaan yang dapat membuat kalimat semakin indah, bagus dan menghiasinya dengan kebaikan dan keindahan setelah kalimat tersebut sesuai dengan situasi dan kondisi dan telah jelas makna yang dikehendaki"1

Dalam ilmu badi' mempelajari cara membentuk kalam yang baik sesudah memelihara muthabaqoh dan kejelasan dalalahnya. Ada dua aspek bidang kajian ilmu badi', yaitu muhassinat lafdziyah (keindahan lafadznya) dan muhasanat ma'nawiyah (keindahan maknyanya). Di dalam muhasinat lafdziyah terdapat satu kajian yang membahas tentang gaya bahasa sastra yang mengutip ayat atau hadits kedalam rangkayan kalimat sastra tersebut tanpa menjelaskan bahwa petikan itu berasal dari al-Qur'an atau hadits.

Banyak kita temukan di beberapa tulisan sastra baik itu berupa sajak ataupun prosa yang mengutip atau menggunakan rangkaian kata yang berasal dari ayat-ayat Al Qur'an maupun hadits nabi saw, namun sangat disayangkan ada diantaranya yang tidak pada tempatnya yang layak (mungkin dikarenakan ketidaktahuan penulis akan hukum iqtibas yang dibolehkan). Banyak juga yang tidak memperdulikan bagaimana mengambil beberapa ayat maupun hadits yang kemudian dimasukan dalam rangkaian sajak ataupun prosa tersebut, tidak mengindahkan mana yang boleh dan mana yang tidak boleh. 
Hal ini perlu menjadi pembahasan yang serius mengingat al-Qur'an adalah kitab suci yang harus terjaga dan dijaga kemurnian dan keaslianya, jangan sampai al-Qur'am diposisikan sama dengan teks-teks sastra pada umumnya.

\section{B. PENGERTIAN IQTIBAS}

Secara bahasa, iqtibas berarti 'menyalin' dan mengutip. Di dalam al Qur'an di sebutkan;

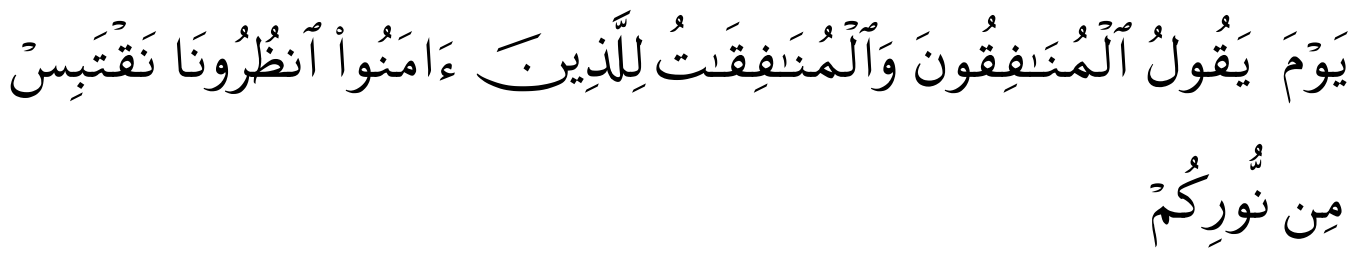

"Pada hari ketika orang-orang munafik laki-laki dan perempuan berkata kepada orang-orang yang beriman: "Tunggulah Kami supaya Kami dapat mengambil sebahagian dari cahayamu".2

Ibnu Faris di dalam Maqayis Lughoh menjelaskan; qabasa terdiri dari huruf $q a f, b a^{\prime}$ dan sin. Pada asalnya menunjukan pada sifat dari sifatsifat api, kemudian kata itu digunakan untuk makan "su'latun nar"mengambil api

Sedangkan secara istilah, iqtibas adalah kalimat yang disusun oleh penulis atau penyair dengan menyertakan petikan ayat atau hadis ke dalam rangkaian kalimatnya tanpa menjelaskan bahwa petikan itu berasal dari Al-Qur'an atau hadis ${ }^{3}$. Oleh karenaya apabila penulis atau penyair menjelaskan bahwa petikan itu dari dari ayat ataupun hadits, maka ia tidak disebut dengan iqtibas. Dalam ilmu badi' Iqtibas merupakan bagian dari muhasanat lafdziyah. Dalam pembahasannya, muhasanat lafdziyah dibagi pada tiga pokok bahasan, yaitu : Jinas, iqtibas dan Syaja'. 
Dalam Ilmu Badi, iqtibas didefinisikan sebagai berikut "Pembicara menyimpan prosa atau puisinya dengan sesuatu dari Al-Qur'an atau Hadits dengan cara yang tidak memberikan isyarat bahwa sesuatu itu berasal dari keduanya." Qaidah Ilmu Badi membolehkan mutakallim (pembicara) merubah sedikit pada kata yang diambil dari Al-Qur'an atau Hadits, yaitu karena untuk penyesuaian wazan atau sebab lainnya.

Keindahan bahasa Al-Qur'an dan keterjagaanya dalam menyimpan makna membuat para penyair tidak khawatir untuk mengutip beberapa kalimat yang diambil dari ayat-ayat Al-Qur'an, karena Al-Qur'an memiliki rangkaian kata sangat indah dan tidak ada yang mampu menandinginya, al Qur'an memiliki makna yang mendalam dan ia senantiasa akan terjaga dari segala perubahan, hal itu menjadikan para penyair merasa tak perlu menyantumkan sumber kutipan yang ditulis dalam syairnya, karena tentu kalimat itu takkan dirasa asing untuk diperdengarkan.

\section{CONTOH IQTIBAS}

Iqtibas dibagi menjadi tiga macam, ialah :

1. Tsabitul ma'ani, yaitu yang tidak berubah dari makna asalnya.

2. Muhawwal, yaitu yang dirubah dari makna asalanya seperti kata syair:

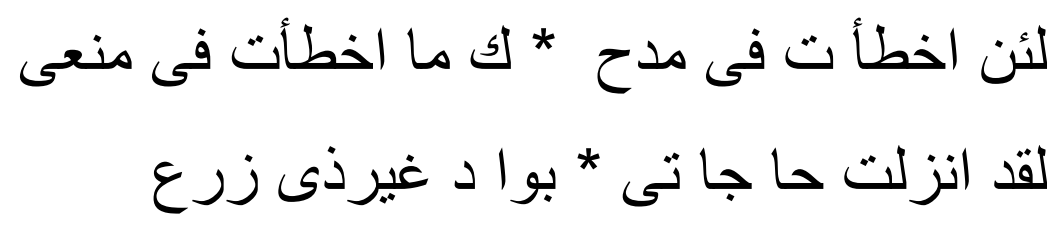


Artinya :

Kalau aku salah dalam memujimu, maka aku tidak salah dalam menahan nafsuku. Sungguh engkau telah menempatkan kebutuhanku pada lembah yang tidak ada tumbuh-tumbuhannya.

Syi'ir ini dikutip dari ayat :

$$
\text { ربنا انى اسكنت من ذربتى بو ادغير ذى زرع. }
$$

Maknanya dalam Al-Qur'an, ialah lembah yang tidak berair dan tidak ada tumbuh-tumbuhannya, yaitu: Mekkah. Adapun maksud syi'ir ini adalah, ialah laki-laki yang tiada kebaikannya dan tiada berguna.

3. Yang dirubah sedikit wacannya, seperti kata sya'ir :

$$
\text { قد كا ن ما خفت ان بكو نا انا الى الله را جعونا. }
$$

Artinya :

Sungguh telah terbukti apa yang engkau takuti. Sesungguhnya kami kembali semua kepada Allah. Dari ayat :

$$
\text { الله وان اليه را جعون. }
$$

\section{CONTOH-CONTOH}

a. Abdul Mu-min Al-Ashfahani4

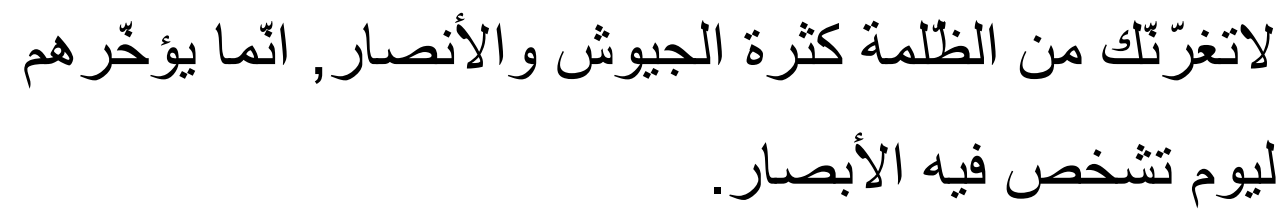

“Jangan sekali-kali kamu terbujuk oleh banyaknya pasukan dan pembantu orang-orang penganiaya. Sesungguhnya kami menangguhkan mereka sampai suatu hari yang pada waktu itu mata (mereka) terbelalak." 
Yang diiqtibas oleh Imam Al-Ashfahani adalah kalimat Innamā nu'akh-khiruhum liyaumin taqsykhashu fiihil abshār dengan sedikit perbedaan pada dhamir huwa (yuakh-khiruhum) pada fiil mudharinya menjadi dhamir nahnu (nuakh-khiruhum). Ini adalah iqtibas dari Surah Ibrahim ayat 42.

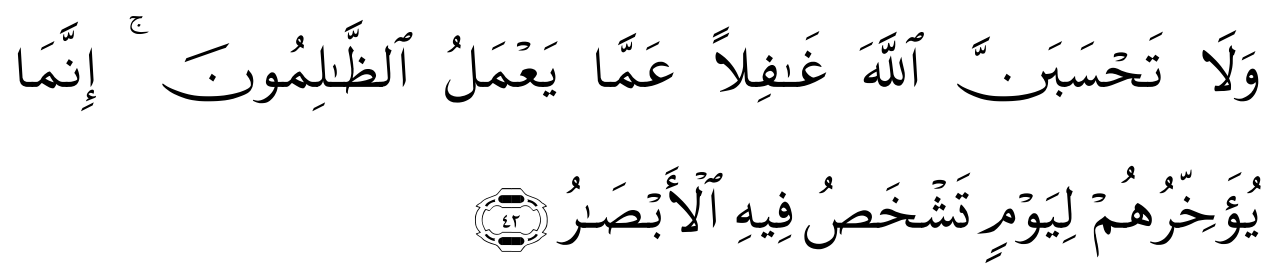

“Dan janganlah sekali-kali kamu (Muhammad) mengira, bahwa Allah lalai dari apa yang diperbuat oleh orang-orang yang zalim. Sesungguhnya Allah memberi tangguh kepada mereka sampai hari yang pada waktu itu mata (mereka) terbelalak," (QS: Ibrahim Ayat: 42)5

b. Iqtibas yang dilakukan oleh Nabi Saw: Allahumma ghāratin-nujū mu wa hadaatil 'uyūnu wa anta al-hayyul qayyū mu lā ta'khuduka sinatun wa lā naum yā hayyu yā qayyūmu ahdi' lailiy wa anmi 'ainiy." Ya Allah, bintang-bintang telah lenyap dan mata telah tenang sedangkan Engkau Tuhan Yang Maha Hidup kekal dan selalu mengurusi makhluk-Nya. Engkau tidak dapat dikalahkan oleh kantuk dan tidak pula oleh tidur. Ya Tuhan yang hidup kekal, ya Tuhan yang selalu mengurusi makhluk-Nya, tenangkanlah malamku dan tidurkan mataku."(H.R. Thabrani dan Ibnu Suni)

Perhatikan kalimat-kalimat yang digaris bawahi, itulah iqtibas, kemudian bandingkan kalimat-kalimat tersebut dengan beberapa kalimat dari Ayat Kursi. 
c. Contoh iqtibas yang dilakukan Sayyidina Ali ra: Alā innallaha qad kasyafal khalqa kasyfatan lā annahu jahila mā akhfauhu min mashūbi asrārihim wa makūni dhamāirihim walākin liyabluwahum ayyuhum ahsanu 'amalan. "Ingatlah, sesungguhnya Allah benar-benar telah mengetahui makhluk-Nya tentang semua kondisinya hanya dengan satu kali penyingkapan saja, Dia tidak bodoh dari apa yang mereka sembunyikan dari-Nya, yakni dari rahasiarahasia dan hati-hati mereka yang disembunyikan. Akan tetapi agar Dia menguji siapakah di antara mereka yang lebih baik amalnya." 6

Bandingkanlah kata-kata yang digaris bawahi di atas dengan katakata dari ayat 7 Surat Hud :
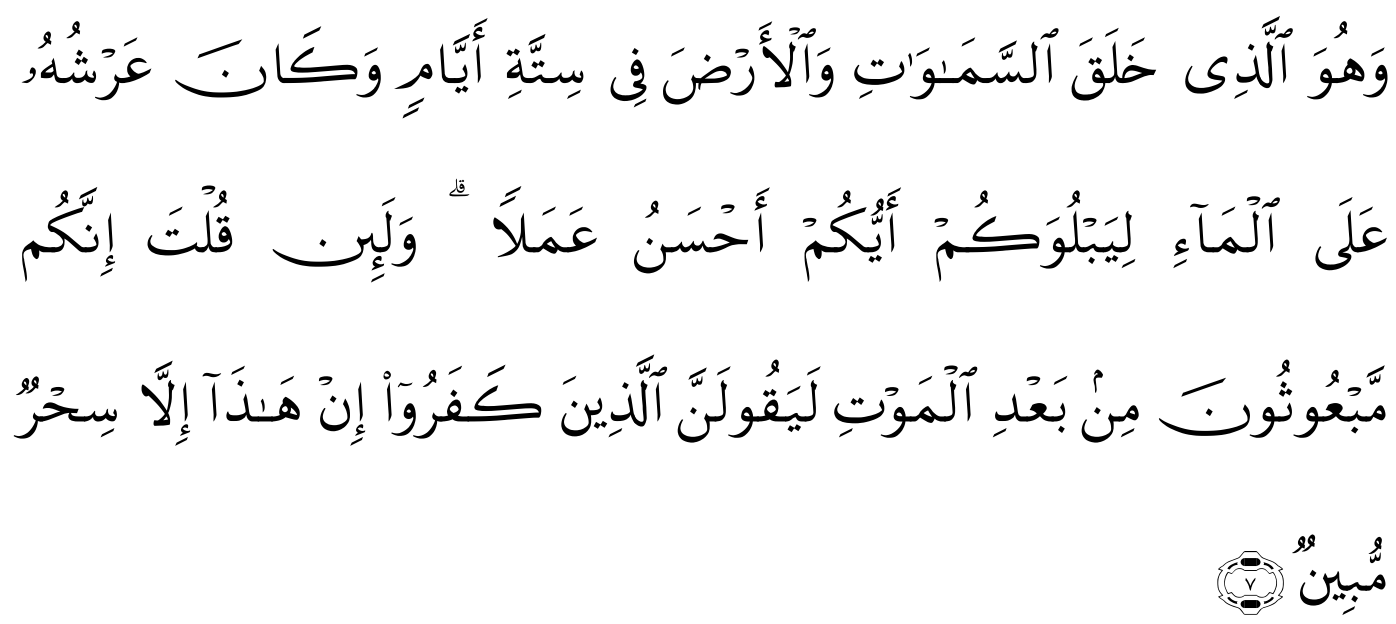

Dan Dialah yang menciptakan langit dan bumi dalam enam masa, dan adalah singgasana-Nya (sebelum itu) di atas air, agar Dia menguji siapakah di antara kamu yang lebih baik amalnya, dan jika kamu berkata (kepada penduduk Mekah): "Sesungguhnya kamu akan dibangkitkan sesudah mati", niscaya orang-orang yang kafir itu akan berkata: "Ini tidak lain hanyalah sihir yang nyata".(QS: Huud Ayat: 7). 


\section{PANDANGAN ULAMA' TERHADAP IQTIBAS DENGAN AYAT AL QUR'AN DAN SUNAH NABI PADA SAJA' DAN PROSA}

\section{HUKUM IQTIBAS DARI AL QUR'AN}

Para ulama membedakan antara iqtibas dalam sajak dan iqtibas dalam prosa, para ulama klasik dan moderen bersepakat iqtibas dalam sajak diharamkan atau minimal makruh, dengan tujuan untuk menjaga kemurnian al Qur'an dari penisbahan dengan al Qur'an, hal tersebut berdasarkan firman Allah

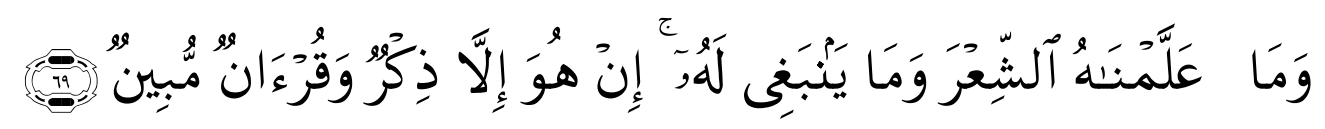

“dan Kami tidak mengajarkan syair kepadanya (Muhammad) dan bersyair itu tidaklah layak baginya. Al Quran itu tidak lain hanyalah pelajaran dan kitab yang memberi penerangan. (Q.S. Yassin; 69)

Berkata imam Suyuthi di dalam kitab al itqon :" ini semua menunjukan pada bolehnya iqtibas pada prosa dalam bentuk nasehat, pujian dan do'a dan tidak dibolehkan dalam sajak dan diantara keduanya ada perbedaan dalam hal ini, Qodhi Abu Bakar yang bermazhab maliki membolehkan, adapun ulama kontemporer yang mengharamkan diantaranya adalah syekh Ibnu al Utsaimin, beliau berpendapat makruh di dalam sajak dan boleh di dalam prosa. Beliau menjelaskan di dalam kitab Syarhul balaghah :"adapun apabila iqtibas di dalam sajak, apabila ia sama dengan makna yang dimaksud maka itu jelas bagiku, hal tersebut tidak boleh dan terlarang, karena hal tersebut membuat rancuh al qur'an dengan sajak, dan denganya orang-orang bisa tergelincir dalam pengagungan dan penghormatan terhadap sajak tersebut. 
Syaikh Alamah Abdul Muhsin Abad di dalam kajiannya tentang sunan tirmidzi pernah ditanya, ia berpendapat : Al'Quran itu tidak boleh dijadikan bagian dari sajak (dikutip untuk menjadi bagian dari sebuah sajak), namun sebagian ulama ada yang terkadang menjadikan bait sajaknya dari al-Qur'an dan kita tidak meragukanya lagi untuk meninggalkan hal tersebut dan menjauhinya itu lebih baik.

Sebagian ulama yang lain membolehkan iqtibas dengan alQur'an di dalam sajak apabila tidak mengandung makna yang terlarang, seperti bentuk-bentuk nasehat, tadzkiroh atau pemujian terhadap rasulullah saw. Namun ada sebagian yang bimbang dengan hal tersebut, dikarenakan Ustadz Abu Mansur Al Isfirayaini membolehkan, mereka beralasan dengan beberapa bait sajak beliau mengabil dari ayat-ayat Al-Qur'an, maka berkatalah imam Suyuthi di dalam Kitab Al Itqon:" Syaikh Tajuddin Bin Subki di dalam tulisanya tentang Imam Abu Mansur Abdul Qohar bin Thohir At Tamimi al Baghdadi salah seorang pembesar ulama bermadzhab Syafi'i, bahwasanya sajakanya berbunyi :

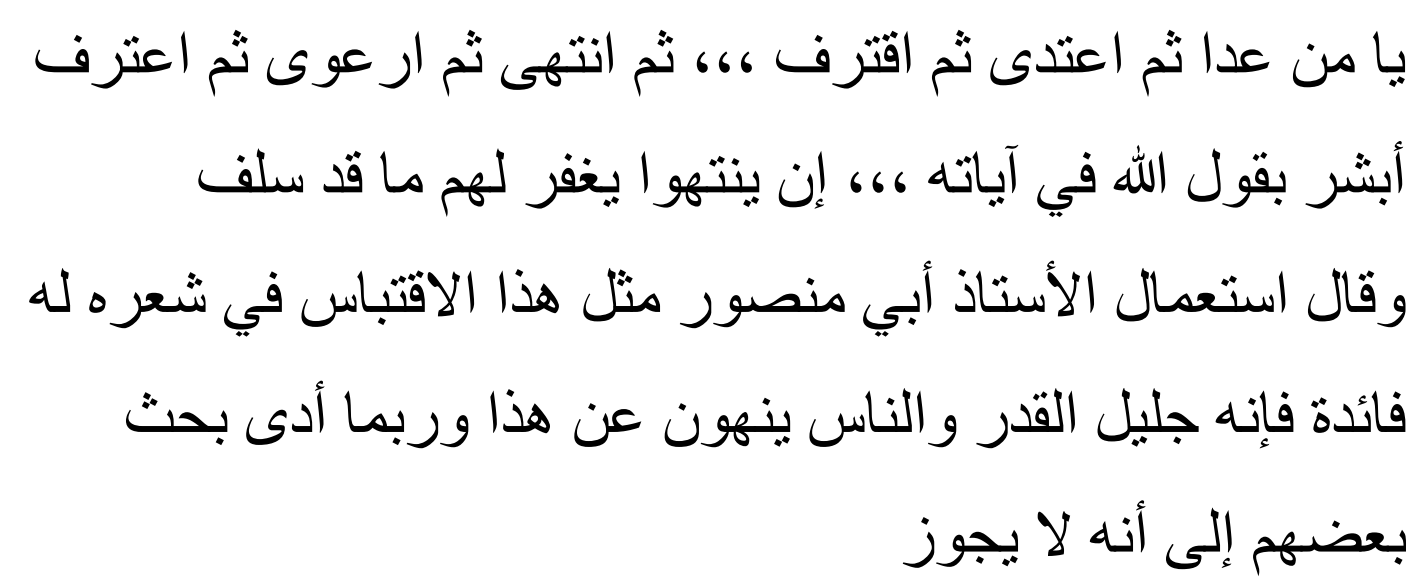

Abu Mansur di dalam sajaknya ini menggunakan Iqtibas hal tersebut memiliki faedah, bahwasanya ia jelas dalam meletakan batasan dan orang lain dilarang dalam hal ini 
Adapun iqtibas di dalam prosa dibolehkan dengan memperhatikan beberapa syarat, hal tersebut berdasarkan bahwa banyak sekali haditshadits nabi yang menggunakan sebagian dari ayat-ayat al Qur'an, seperti hadits nabi saw:

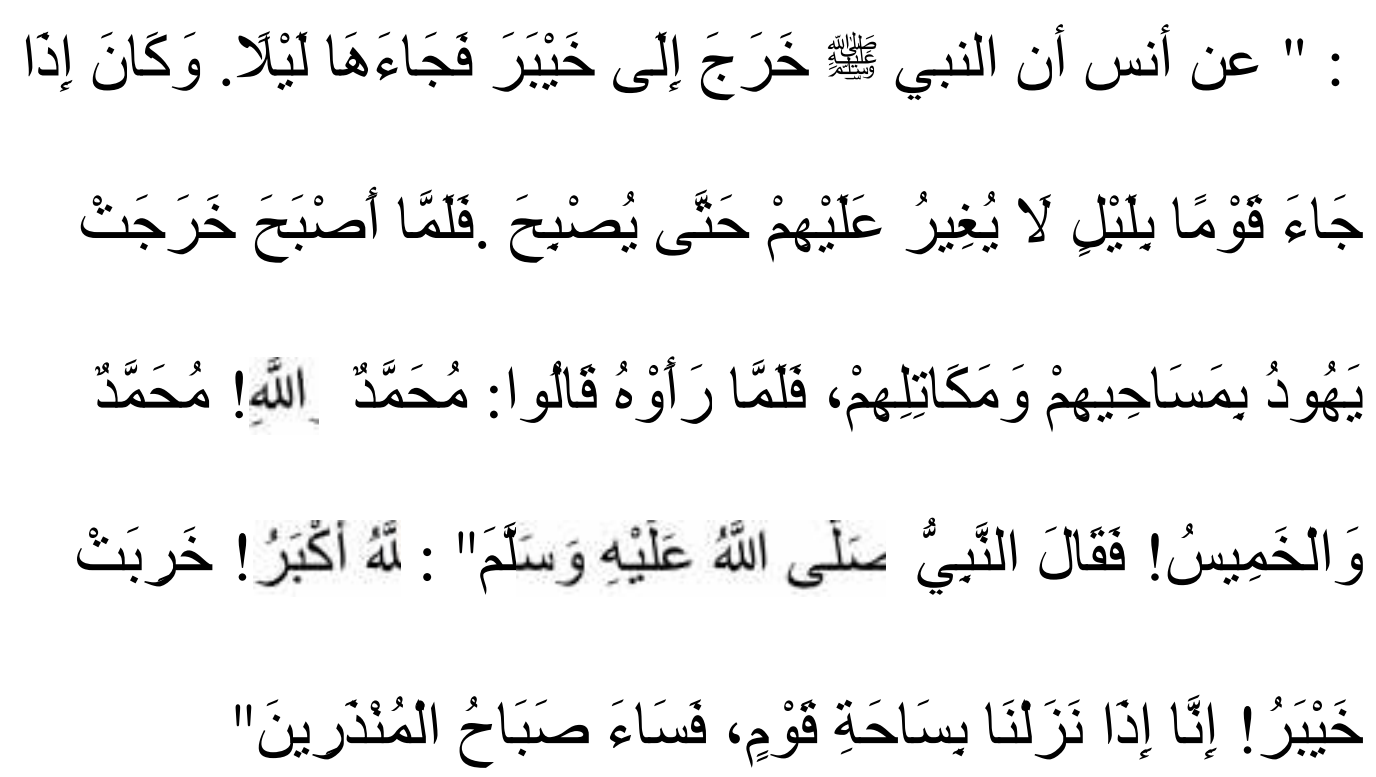

Dari Anas, bahwasanya nabi saw ketika ia berangkat menuju Khaibar dan Beliau mendatanginya di malam hari. Dan Beliau apabila mendatangi suatu kaum di malam hari Beliau tidak langsung menyerang mereka hingga menunggu datangnya waktu shubuh. Ketika tiba waktu shubuh, orang-orang Yahudi keluar dengan membawa sekop-sekop dan keranjang mereka. Tatkala melihat Nabi , mereka berkata: “Muhammad. Demi Allah Muhammad dan pasukannya". Maka Nabi bersabda: "Allahu Akbar, hancurlah Khaibar. Sesungguhnya kami apabila mendatangi perkampungan suatu kaum, maka amat buruklah pagi hari yang dialami orang-orang yang diperingatkan tersebut." 
Berkata imam nawawi dalam syarh muslimnya, Perkataan nabi saw “Sesungguhnya kami apabila mendatangi perkampungan suatu kaum, maka amat buruklah pagi hari yang dialami orang-orang yang diperingatkan tersebut". Di dalam kalimat tersebut terdapat kata Saaha yang memiliki persamaan kata dengan fina'(halaman/pekarangan) yang aslinya berarti fidha' yaitu ruangan yang ada diantara tempat tinggal. Dalam konteks ini, diperbolehkan untuk mengutip Al-Qur'an dalam halhal yang telah dijamin. Dan sudah banyak teori-teori yang menjelaskan hal tersebut, sebagaiaman ketika rasul melakukan penaklukan kota Makka beliau mengucapkan kata-kata yang bertujuan untuk menusuk berhalaberhala yang ada dengan ucapnya;

\section{جاء الحق وما يبدئ الباطل وما يعيد جاء الحق وزهق الباطل}

"telah datang kebenaran maka tenggelamlah kebatilan, apabila kebenaran itu sudah kembali akan musnahlah kebatilan"

Para ulama bersepakat, apabila pengutipan itu dengan tujuan untuk olok-olokan, penghinaan dan canda gurau hal tersebut dilarang sebagai bentuk pemuliaan kepada kitabullah.

Berkata imam suyuthi di dalam tanwir al hawalik syarah muwatho' imam malik (jild.1 hlm.312)

"Sesungguhnya kami apabila mendatangi perkampungan suatu kaum, maka amat buruklah pagi hari yang dialami orang-orang yang diperingatkan tersebut". Di dalam kalimat tersebut terdapat kata Saaha yang memiliki persamaan kata dengan fina'(halaman/pekarangan) yang 
aslinya berarti fidha' yaitu ruangan yang ada diantara tempat tinggal. Hadits ini menjadi dasar yang kuat dalam bolehnya mengutip dan iktibas dengan ayat, pendapat ini dikuatkan oleh ibnu Abdul Bar di dalam tamhid, ibnu Rasyiq di dalam syarah al Muwatho' dan keduanya adalah ulama dari madzhab maliki, dan imam nawawi di dalam syarah muslim mereka semua memiliki penjelasan tentang hadits ini dan tidak diketahui diantara kaum muslimin yang menyelisihi tentang bolehnya iqtibas dalam bentuk prosa asalkan tidak dalam bentuk candaan, ucapan mesum, gurauan, kefasikan, sambil minum-minum khomer dan sebagainya. Para imam madzhab telah menunjukan isyarat pembolehan yaitu berupa teksteks khutbah, tulisan-tulisan dan berbagai macam bentuk karya tulis dan hal tersebut juga dilakukan oleh para sahabat, seperti Abu Bakar, Umar, Ali dan kedua anaknya, Abdullah bin Mas'ud dan sahabat-sahabat lainya dan para tabi' in dan mereka setelah mereka dan banyak juga ditemukan di beberapa hadits-hadits sohih nabi saw.

\section{E. KESIMPULAN PENUTUP}

Iqtibas merupakan salah satu bentuk dari keindahan lafadz dalam sebuah teks, bahasa dan sastra Arab sangat memperhatikan persoalan keindahan dari sisi teks, namun keindahan tersebut mengahmbil dari teks al-Qur'an yang notaben harus tunduk kepda syari'at. Iqtibas dengan teks al-Qur'an dan sunah tidak dilarang dan diharamkan secara mutlak, hal tersebut dibolehkan namun harus dengan kehati-hatian. Wajib bagi mereka yang ingin menggunakan iqtibas mengetahui hukum-hukum mana yang boleh dan mana yang tidak boleh agar tidak terjatuh kedalam kesalahan dan pelecehan terhadap al Qur'an. 
Penulis : Erwin Suryaningrat. M.Hum adalah Dosen Fiqhul Lughah pada IAIN Bengkulu.

\section{DAFTAR PUSTAKA}

Qurtubi, Imam, Tafsir Qurtubi, Beirut. Dar al Kutub Al Ilmiyah, 2010

Suyuthi, Imam, Al Itqon fi Ulumil Qur'an, Beirut. Darul Kutub Ilmiyah.2004

Khazanatul adab wa ghayatul arab, Ibnu Hajaj Al Hamawi

al Qozuni, Khotib, Al Iidhoh fi Ulumil Balaghah, Beirut. Darul Kutub Al Ilmiyah,1971

Ali Al-Jarim \& Musthafa Amin, Terjemahan Al-Balaaghatul Waadhihah, cet1,Bandung Sinar Baru Algensindo 1994

Syuthi, Imam, Tanwirul Hawalik, Semarang, Toha Putra.t.t

Syarah Muwatho' Imam Malik

Sarah Muslim Imam nawawi

Maqayis Lughoh Ibnul Faris

Tadzhibul Lughoh, Imam Azhari

Syarah Balagah, Syekh ibnu Utsaimin 
${ }^{1}$ Dr. Abdul Azizi Atiq, fil balaghah al arabiyah. Ilmu badi' (dar nahdhoh Al Arabiyah: Beirut.). Hlm: 7

${ }^{2}$ Q.S> Al Hadid: 13

${ }^{3}$ Ali Al-Jarim \& Musthafa Amin, Terjemahan Al-Balaaghatul Waadhihah, cet1,(Bandung Sinar Baru Algensindo 1994), hal. 386

4 Abdul Mu-min Al-Ashfahani adalah seorang sastrawan Arab yang kondang dan juga seorang mutashawwif (ahli tasawwuf).

5 Ali Al-Jarim \& Musthafa Amin, Terjemahan Al-Balaaghatul Waadhihah, cet1,(Bandung Sinar Baru Algensindo 1994), hal 385.

${ }^{6}$ Nahjul Balaghah, Darul Hijrah, Qum, Iran, hal 200-201. 